\title{
An Unusual Congenital Anomaly in Fanconi Aplastic Anemia: Congenital Lobar Emphysema
}

\author{
Fanconi Aplastik Anemisinde Nadir Bir Konjenital Anomali: Konjenital Lober Amfizem
}

Ali Fettah¹, Gökçe Pınar Reis¹, Soner Sertan Kara², Tekin Aksu³, Afak Durur Karakaya4, Mahmut Subaşı5, Atilla Çayır6

${ }_{1}^{1}$ Erzurum Regional Training and Research Hospital, Clinic of Pediatric Hematology, Erzurum, Turkey

2Erzurum Regional Training and Research Hospital Clinic of Pediatric Infectious Disease, Erzurum, Turkey

${ }^{3}$ Dr. Abdurrahman Yurtaslan Oncology Training and Research Hospital, Clinic of Pediatric Hematology, Ankara, Turkey

${ }^{4}$ Erzurum Regional Training and Research Hospital, Clinic of Radiology, Erzurum, Turkey

${ }^{5}$ Erzurum Regional Training and Research Hospital, Clinic of Thoracic Surgery, Erzurum, Turkey

${ }^{6}$ Erzurum Regional Training and Research Hospital, Clinic of Endocrinology, Erzurum, Turkey

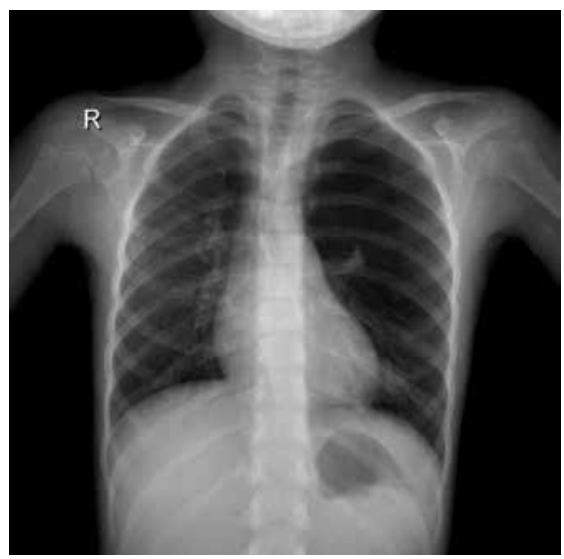

Figure 1. Posterior anterior lung radiography imaging of the patient.

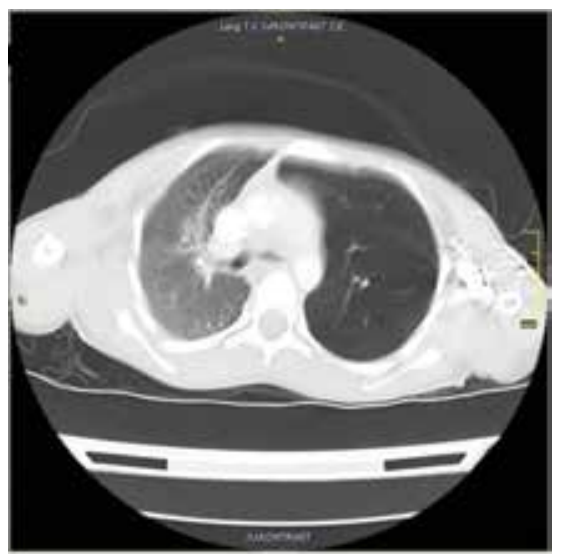

Figure 2. Computerized tomography imaging of the patient.
A 7-year-old girl who presented with epistaxis was examined due to pancytopenia. Her medical history revealed that she had respiratory distress in the neonatal period. She was born to a second-degree consanguineous marriage. Physical examination revealed short stature, microcephaly, microphthalmia, and hypo/ hyperpigmented lesions on the trunk and extremities. She did not have tachypnea, but she had decreased breathing sounds in the left lung. A laboratory work-up revealed hemoglobin of 5.4 $\mathrm{g} / \mathrm{dL}$, mean corpuscular volume of $103 / \mathrm{fL}$, leukocyte count of $2.7 \times 10^{9} / \mathrm{L}$, and thrombocyte count of $11 \times 10^{9} / \mathrm{L}$. A chromosomal breakage test with diepoxybutane was compatible with Fanconi anemia (FA). Posteroanterior chest $X$-ray showed hyperinflation of the left lung (Figure 1). Chest computed tomography revealed emphysematous changes in the upper part of the left lung, compatible with congenital lobar emphysema (Figure 2).

FA is a rare autosomal recessive disorder and presents with numerous organ abnormalities, progressive cytopenia, and susceptibility to several malignancies [1,2]. Although absent lung lobes and abnormal pulmonary drainage have been reported [3], congenital lobar emphysema has not been presented as an accompanying pathology with FA. It is striking that the patient had no prominent respiratory symptoms since the newborn period. Congenital lobar emphysema's association with FA has not been reported previously and it could be in coexistence or have an association with FA. 
Keywords: Fanconi, Anemia, Congenital lobar emphysema

Anahtar Sözcükler: Fanconi, Anemi, Konjenital lober amfizem

\section{Ethics}

Informed Consent: It was taken.

\section{Authorship Contributions}

Surgical and Medical Practices: Tekin Aksu, Afak Durur Karakaya, Mahmut Subaşı, Atilla Çayır; Concept: Ali Fettah, Gökçe Pınar Reis; Design: Ali Fettah, Gökçe Pınar Reis; Data Collection or Processing: Ali Fettah, Gökçe Pınar Reis, Soner Sertan Kara, Tekin Aksu, Afak Durur Karakaya, Mahmut Subaşı, Atilla Çayır; Analysis or Interpretation: Ali Fettah, Gökçe Pınar Reis, Soner
Sertan Kara; Literature Search: Ali Fettah, Gökçe Pınar Reis, Soner Sertan Kara; Writing: Ali Fettah, Soner Sertan Kara.

Conflict of Interest: The authors of this paper have no conflicts of interest, including specific financial interests, relationships, and/or affiliations relevant to the subject matter or materials included.

\section{References}

1. Unal $S$, Ozbek N, Kara A, Alikaşifoğlu M, Gümrük F. Five Fanconi anemia patients with unusual organ pathologies. Am J Hematol 2004;77:50-54.

2. Auerbach AD. Fanconi anemia and its diagnosis. Mutat Res 2009;668:4-10.

3. Bessler M, Mason PJ, Daniel CL, Wilson DB. Inheritedbone marrow failure syndromes. In: Nathan DG, Oski FA (eds). Hematology of Infancy and Childhood. Philadelphia, Saunders, 2015. 